16

\title{
Спектральные оптические свойства керамических нанопористых мембран на основе анодного оксида алюминия и покрытия из серебра в парах аммиака
}

\author{
(С) М.Ю. Васильков ${ }^{1,2}$, И.Н. Михайлов ${ }^{1,2}$, Ю.В. Никулин ${ }^{1,3}$, С.С. Волчков ${ }^{2}$, Д.А. Зимняков ${ }^{2}$, Н.М. Ушаков $^{1,3}$ \\ ${ }^{1}$ Институт радиотехники и электроники им. В.А. Котельникова РАН, Саратовский фиилиал, \\ 410019 Саратов, Россия \\ ${ }^{2}$ Саратовский государственный технический университет им. Гагарина Ю.А., \\ 410008 Саратов, Россия \\ ${ }^{3}$ Национальный исследовательский университет им. Н.Г. Чернышевского, \\ 410012 Саратов, Россия \\ ฯ e-mail: vasilk.mikhail@yandex.ru
}

Поступила в редакцию 29.04.2021 г.

В окончательной редакции 22.06.2021 г.

Принята к публикации 08.11.2021 г.

\begin{abstract}
Экспериментально исследованы спектральные оптические свойства синтезированных керамических нанопористых мембран на основе анодного оксида алюминия и покрытия из серебра в насыщенном газовом потоке аммиака. На основе измеренных спектров пропускания и выявленной интерференционной части спектров в диапазоне длин волн от 550 до $900 \mathrm{~nm}$ получены временные и спектральные зависимости эффективной оптической толщины и её изменений в неравновесных условиях за счет адсорбции молекул аммиака на поверхности серебряной плёнки. По обнаруженным и измеренным сдвигам интерференционных максимумов до $14 \mathrm{~nm}$ в спектрах пропускания мембраны в газовом потоке аммиака показана возможность построения оптических селективных сенсоров интерференционного типа с временем отклика $10-15 \mathrm{~min}$.
\end{abstract}

Ключевые слова: пористый анодный оксид алюминия, мембрана, плёнка серебра, интерференция света, аммиак, эффективная оптическая толщина, сдвиг интерференционных максимумов.

DOI: $10.21883 / \mathrm{OS} .2022 .02 .52000 .2244-21$

\section{Введение}

Пористый анодный оксид алюминия (ПАОА), полученный простым методом электрохимического анодирования и характеризующийся большой площадью удельной поверхности, высокой упорядоченностью и возможностью контроля параметров структур, привлекает значительное внимание в последние десятилетия [1]. Пористые пленки анодного оксида алюминия (AOA) широко исследованы для создания на их основе оптических сенсоров на явлениях флуоресценции, поверхностноусиленного комбинационного рассеяния света (SERS) и поверхностного плазмонного резонанса (SPR), а также с помощью отражательной интерферометрической спектроскопии (RIfS) [2,3]. Метод отражательной интерферометрической спектроскопии основан на отражении белого света от двух границ пористых структур, что приводит к усилению отраженного светового сигнала на длинах волн, соответствующих оптическим модам резонатора Фабри-Перо (FP), образованного системой тонкая пленка - окружающая среда (эффект Фабри-Перо) [4]. Адсорбция молекулярных частиц на поверхности поры вызывает изменение показателя преломления в структуре и сдвиг длины волны интерферометрических полос, которые можно обнаружить и количественно оценить [5]. Существенные преимуще- ства нанопористой платформы АОА по сравнению с плоскими полимерными пленками, ранее применяемыми для метода RIfS, заключаются в обеспечении уникальной трехмерной морфологии структур пор, позволяющей проводить её модификацию различными материалами и создавать селективные высокочувствительные активные поверхности для биомолекулярных и газовых сенсорных применений [6]. Первые работы по использованию метода RIfS с использованием ПАОА были посвящены чувствительному биомолекулярному обнаружению примесей в водных растворах [7,8], но его применение для обнаружения молекул газа или пара было реализовано только в последнее десятилетие $[9,10]$. Предполагается, что смещение интерференционных полос при взаимодействии с молекулами газа вызвано двумя явлениями: адсорбцией газа на пористой поверхности и заполнением пор за счет капиллярной конденсации [11]. Оба эти эффекта потенциально могут применяться для обнаружения газа или пара в зависимости от физических и химических свойств детектируемых молекул. Однако большинство газов не конденсируется внутри пор. Для обнаружения этих газов необходимо добиться их связывания с поверхностью ПАОА. Сильная адсорбция молекул газа на границе раздела ПАОА/воздух способна изменить оптические свойства пористого слоя и вызвать сдвиг интерференционного сигнала. Для достижения 


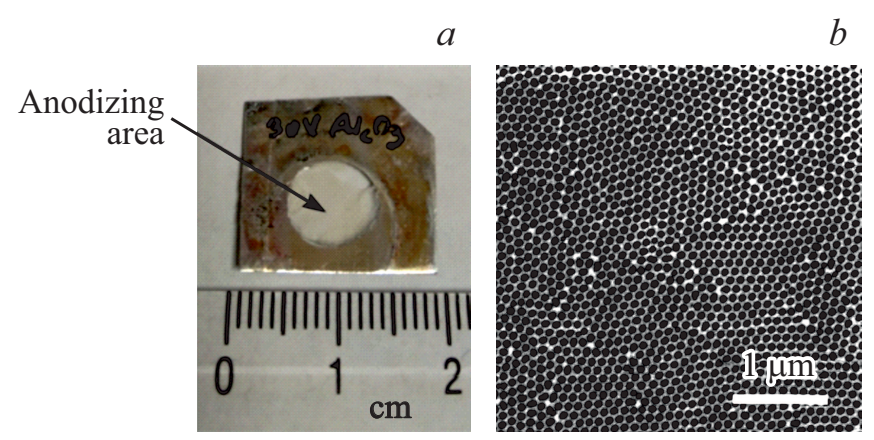

Рис. 1. Внешний вид $(a)$ и СЭМ-микрофотография поверхности мембраны ПАОА $(b)$, полученной анодированием в $0.3 \mathrm{M}$ $\mathrm{H}_{2} \mathrm{C}_{2} \mathrm{O}_{4}$ при температуре $2-4^{\circ} \mathrm{C}$ и напряжении $30 \mathrm{~V}$.

этого условия необходимо сенсибилизировать поверхность пор ПАОА тонкими металлическими пленками, которые обладают хорошим сродством к адсорбции определенных молекул газа и не оказывают значительного влияния на оптические свойства исходной структуры. Для демонстрации этой концепции в работе [9] были нанесены две различные металлические плёнки ( $\mathrm{Au}$ и $\mathrm{Pt})$ на ПАОА и показано обнаружение с их помощью водорода $\left(\mathrm{H}_{2}\right)$ и сероводорода $\left(\mathrm{H}_{2} \mathrm{~S}\right)$. В подтверждение этой концепции необходимо выбрать пару металл-газ с высоким сродством к адсорбции молекул газа на поверхности металла. При этом в работе изучались интерференционные свойства мембран ПАОА в равновесном установившемся режиме адсорбции газов. Интерес также представляет изучение неравновесных интерференционных свойств мембраны ПАОА с разным сочетанием пары металлическая плёнка-газ. Одной из таких пар, на наш взгляд, могут служить тонкая пленка серебра и аммиак. Следует отметить, что работ по исследованию сенсорных устройств к аммиаку, построенных на различных физических (оптических) принципах, опубликовано незначительное количество. Известна работа [12], в которой исследовались сенсорные устройства, изготовленные из гибридных композитов $\mathrm{Fe}_{3} \mathrm{O}_{4} / \mathrm{MW}-\mathrm{CNT}$-PhCOOH с различным содержанием железной окалины при низкой температуре, а также некоторые другие $[13,14]$.

Целью данной работы является экспериментальное исследование зависимости интерференционных свойств мембраны ПАОА, покрытой тонкой плёнкой серебра, от времени нахождения в динамическом газовом потоке аммиака.

\section{Материалы и методы}

Исходным материалом для получения композита ПАОА $+\mathrm{Ag}$ являлась алюминиевая фольга $(99.9 \%)$ толщиной $\sim 100 \mu \mathrm{m}$. Для подготовки и структурирования поверхности субстрата с целью формирования упорядоченной системы пористых каналов проводилось первичное анодное окисление алюминия. Процесс осуществлялся в $0.3 \mathrm{M}$ растворе $\mathrm{H}_{2} \mathrm{C}_{2} \mathrm{O}_{4}$ в электрохимической ячейке из инертного материала при температуре $2-4^{\circ} \mathrm{C}$ в двухэлектродном режиме. Рабочий образец из алюминия подключался к положительному полюсу источника тока (аноду), стальной перфорированный электрод равной площади - к отрицательному полюсу (катоду). На электроды, расстояние между которыми составляло $10-15 \mathrm{~mm}$, подавалось постоянное напряжение в диапазоне $(30 \pm 1) \mathrm{V}$ и выдерживалось в течение $15-20 \mathrm{~h}$. Полученный после первичного анодирования тонкий слой $\mathrm{Al}_{2} \mathrm{O}_{3}$ на поверхности металла имел неупорядоченную пористую структуру (,жертвенный слой“) и подвергался удалению с помощью химического травления при $85-90^{\circ} \mathrm{C}$ в водном растворе $\mathrm{CrO}_{3}$ (puriss.) и $\mathrm{H}_{3} \mathrm{PO}_{4}$ $(80 \%)$ с концентрацией компонентов $20 \mathrm{~g} / 1$ и $35 \mathrm{ml} / 1$ соответственно.

Подготовленный после химического травления металл подвергался второму анодированию в течение $1 \mathrm{~h}$ в условиях, аналогичных первичному анодному окислению, в результате чего была сформирована упорядоченная пористая структура $\mathrm{Al}_{2} \mathrm{O}_{3}$ на поверхности $\mathrm{Al}$. Для придания образцу ПАОА оптической прозрачности металлический подслой при комнатной температуре растворялся в смеси, содержащей $45 \mathrm{ml} / 1 \mathrm{HCl}(38 \%)$ с добавкой $67.5 \mathrm{~g} / 1 \mathrm{CuCl}_{2}$. В результате были получены тонкие мембраны ПАОА (рис. 1,a), одна сторона которых имела „открытую“ пористую структуру (рис. $1, b$ ), а другая была покрыта сплошным слоем $\mathrm{Al}_{2} \mathrm{O}_{3}$. Для формирования матрицы полых каналов сплошной оксидный слой растворялся в $5 \%$ растворе $\mathrm{H}_{3} \mathrm{PO}_{4}(80 \%)$. Толщина мембраны ПАОА, найденная методом профилометрии, не превышала $4.0 \mu \mathrm{m}$. Средний внутренний диаметр нанопор $\mathrm{Al}_{2} \mathrm{O}_{3}$ составлял $(40.4 \pm 3.6) \mathrm{nm}$ с плотностью упаковки структур $1.8 \cdot 10^{10} \mathrm{~cm}^{-2}$.

Для нанесения серебра применялся метод магнетронного распыления на постоянном токе при следующих рабочих параметрах: $U=364 \mathrm{~V}, I=100 \mathrm{~mA}, L=60 \mathrm{~mm}$, $P_{\text {база }} \sim 4 \cdot 10^{-6}$ Torr, $P_{\text {Ar }} \sim 10^{-3}$ Torr, скорость осаждения $\mathrm{Ag} \sim 20 \mathrm{~nm} / \mathrm{min}$. Оптимальные время распыления и толщина серебряного слоя, найденные в ходе предварительных экспериментов, составили $10 \mathrm{~s}$ и $3.6 \mathrm{~nm}$ соответственно.

Газочувствительные свойства ПАОА $+\mathrm{Ag}$ были изучены на измерительной установке, состоящей из камеры с образцом, газосмесительной и оптической части. Схема оптической части измерительной установки показана на рис. 2. Камера для образца была изготовлена из инертного материала (тефлон) и представляла собой герметичную емкость объемом $\sim 500 \mathrm{ml}$, в стенках которой перпендикулярно друг другу располагались попарно 4 отверстия для подачи и отвода газа и прохождения излучения. В камере находился держатель для образцов (кюветодержатель CUV-UV, Ocean Optics), в который ортогонально излучению помещался плоский образец ПАОА $+\mathrm{Ag}$, и вдоль поверхности образца задавался газовый поток. Для обеспечения газового потока использовался электрический газовый компрессор Omron NE-C28, который постоянным потоком лабораторного 
воздуха через тройной кран подключался к скоростному барботеру Рихтера, заполненному насыщенным водным раствором аммиака $\left(20^{\circ} \mathrm{C}\right)$. Регулирование скорости подачи газовой смеси (воздух с насыщенными парами аммиака) проводилось с помощью тройного крана, один выход которого был соединен с барботером Рихтера, а другой выходил в атмосферу. Подбирая определенную степень открывания выхода на атмосферу, добивались барботирования воздуха через склянку Рихтера с частотой $\sim 100 \mathrm{~min}^{-1}$, что соответствовало скорости поступления газо-воздушной смеси в измерительную камеру с образцом $\sim 170 \mathrm{ml} / \mathrm{min}$. Концентрация паров аммиака $\mathrm{c}\left(\mathrm{NH}_{3}\right)$ в подаваемой газо-воздушной смеси составляла $\sim 440 \mathrm{kppm}, p\left(\mathrm{NH}_{3}\right)=335.5 \mathrm{~mm} \mathrm{Hg}\left(20^{\circ} \mathrm{C}, 101.3 \mathrm{kPa}\right.$, $25 \%$ водный раствор $\mathrm{NH}_{3}$ ).

Спектральные интерференционные измерения оптически прозрачной мембраны ПАОА $+\mathrm{Ag}$ были выполнены на спектрометре Ocean Optics QE65000B с галогендейтериевой лампой DH-2000-BAL (Ocean Optics) под управляющей программой spectrasuite при времени интегрирования $100 \mathrm{~ms}$. Скорость спектральной развертки составляла $7.5 \mathrm{~nm} / \mathrm{ms}$. Метод интерференционной спектроскопии основан на взаимодействии света с оптическими структурами, при котором отраженный или проходящий свет усиливается на определенных длинах волн, создавая характерные интерферометрические спектры за счет эффекта Фабри-Перо. В ПАОА $+\mathrm{Ag}$ эффект Фабри-Перо можно описать уравнением

$$
E O T=2 n_{\mathrm{eff}} L \cos \theta=m \lambda,
$$

где EOT - эффективная оптическая толщина мембраны ПАОА $+\mathrm{Ag}, n_{\text {eff }}$ - эффективный показатель преломления, $L-$ физическая толщина мембраны, $m-$ порядок интерференционных полос, $\lambda$ - длина волны света, $\theta-$

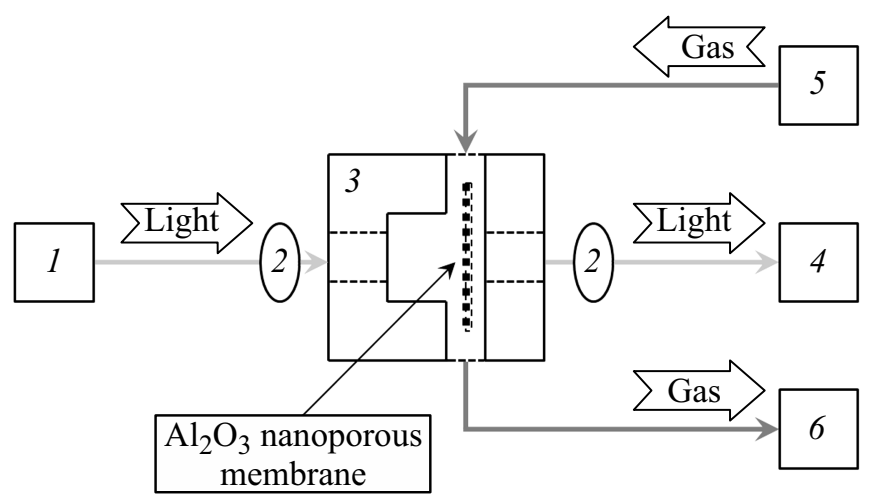

Рис. 2. Схема измерительного стенда для изучения оптических характеристик ПАОА + Ag при воздействии газовой смеси с насыщенными парами аммиака: 1 - источник излучения (lamp), 2 - коллиматор (collimator), 3 - рабочая камера с образцом ПАОА + Ag (samples chamber), 4 - спектрометр (spectrometer), 5 - газосмесительная часть (gas mixing part), 6 - выход в атмосферу (in air). Свет падает нормально на образец в камере.
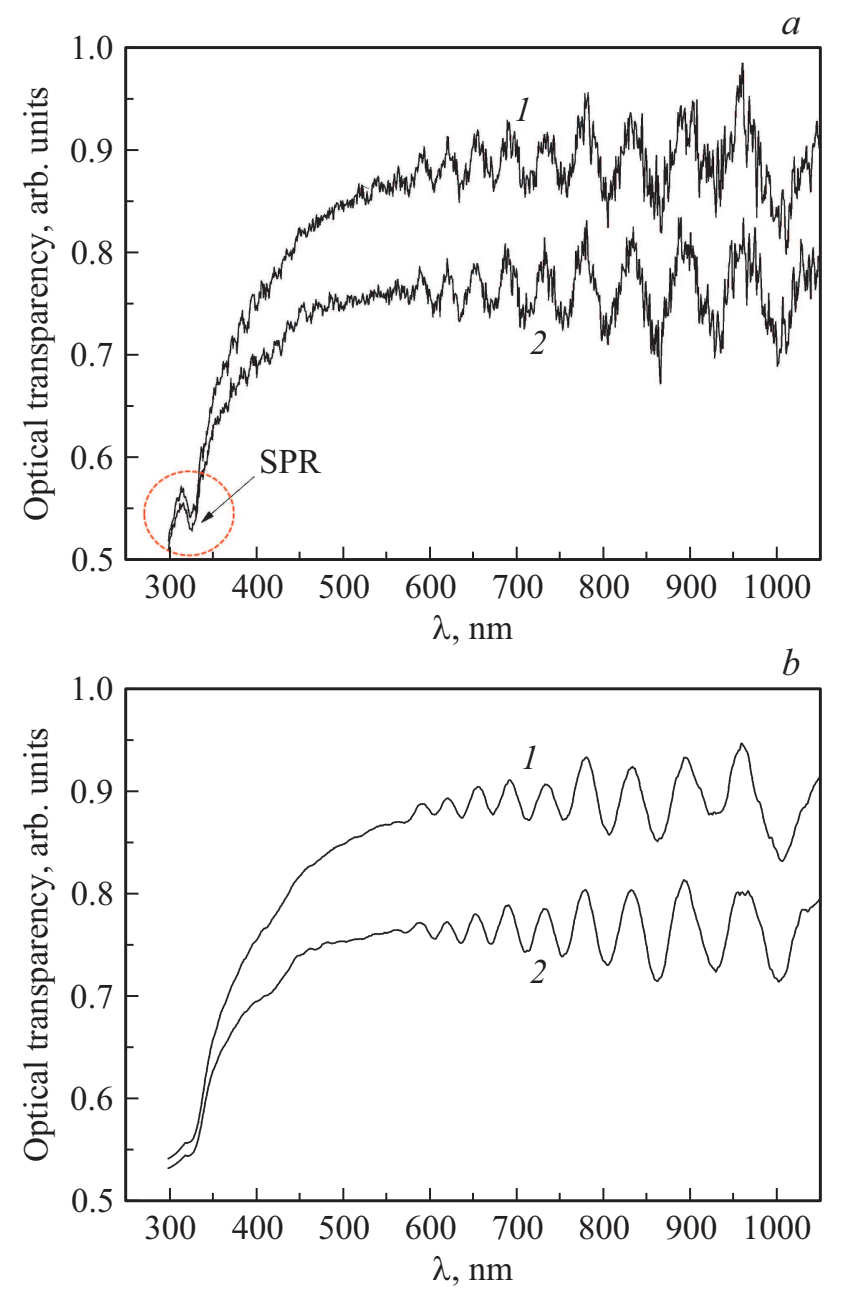

Рис. 3. Спектры прозрачности (пропускания) ПАОА $+\mathrm{Ag}$, измеренные на воздухе и в камере перед напуском газа $(a)$ и те же спектры после обработки $(b)$ : измерение на воздухе $(1)$, измерение в камере в момент напуска газа (2).

угол падения света. Для нормального падения света в нашем случае $\cos \theta=1$.

Выражение (1) можно использовать для количественной оценки изменений в оптических свойствах мембраны, используя изменения эффективной оптической толщины $(D E O T)$ в качестве параметра измерения [15]. Величина DEOT зависит от изменения толщины мембраны за счёт адсорбции молекулярной плёнки на её поверхности и зависимости эффективного показателя преломления мембраны от длины волны падающего света за счет его дисперсии:

$$
\operatorname{DEOT}(t, \lambda)=2 \cos \theta(\Delta d(t) n(\lambda)+d(t) \Delta n(\lambda)) .
$$

Если предположить, что $\Delta d(t) n(\lambda) \ll d(t) \Delta n(\lambda)$, то изменения эффективной оптической толщины $D E O T$ будут в основном определяться эффективным показателем преломления структуры ПАОА $+\mathrm{Ag}+$ молекулярная плёнка адсорбированного газа.

В качестве характеристики обнаружения аммиака на поверхности мембраны ПАОА $+\mathrm{Ag}$ оценивалась $D E O T$ 


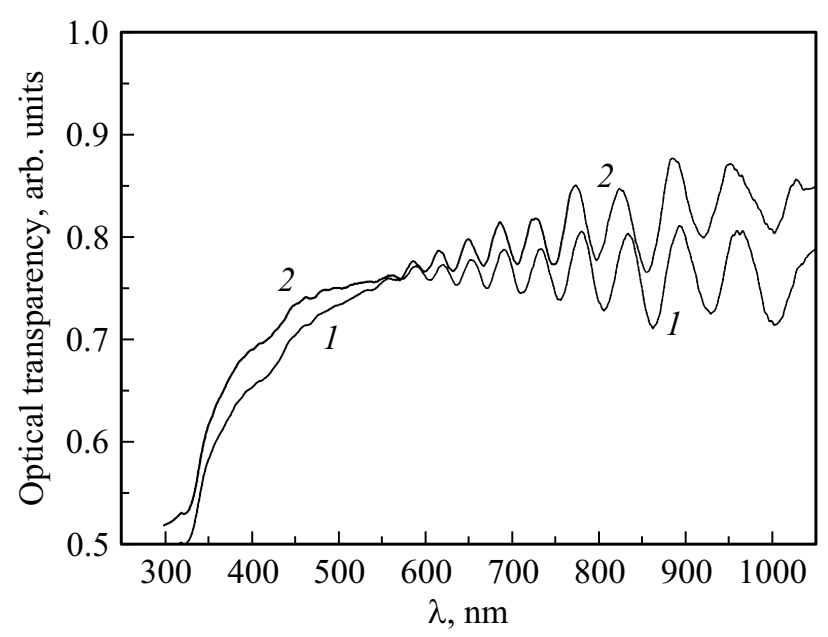

Рис. 4. Спектры прозрачности (пропускания) ПАОА-Ag для разных значений времени напуска газа в измерительную камеру: измерение в камере спустя $2 \min (1), 30 \min (2)$.

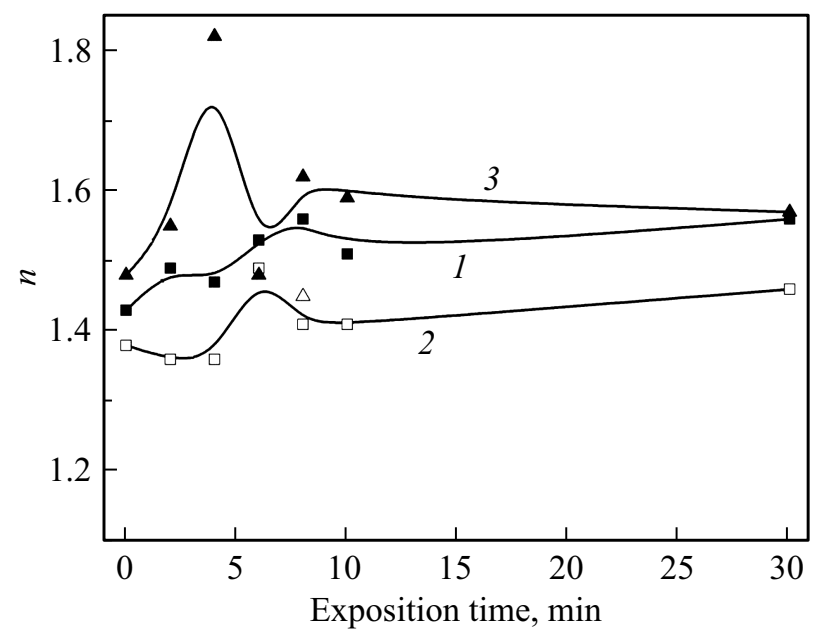

Рис. 5. Зависимости эффективного показателя преломления мембраны ПАОА $+\mathrm{Ag}$ от времени напуска газа в измерительную камеру на длинах волн 650 (1), 750 (2), $850 \mathrm{~nm}$ (3).

в определенный момент времени и на выбранных длинах волн: 650, 750, $850 \mathrm{~nm}$. Общее время экспозиции образцов мембраны ПАОА + Ag в газовом потоке аммиака составляло $30 \mathrm{~min}$. При дискретной временной выборке 0, 2, 4, 6, 8, 10, 30 min проводилось измерение интерферометрических спектров пропускания оптически прозрачной мембраны ПАОА + Ag. При этом время измерения спектра с шириной от 200 до $900 \mathrm{~nm}$ было значительно меньше временного интервала выборки. В предположении малости оптического поглощения в мембране ПАОА $+\mathrm{Ag}$ спектры пропускания $T(\lambda)$ легко трансформировать в спектры отражения $R(\lambda)$, как $R(\lambda)=-1-T(\lambda)$. Применение быстрого фурьепреобразования (БФП) при обработке спектров отражения позволяет получить информацию о процессах адсорбции в данный момент времени.

\section{Экспериментальные результаты и их обсуждение}

Были получены зависимости пропускания образца ПАОА + Ag в диапазоне от 200 до $900 \mathrm{~nm}$ в атмосфере воздуха и в присутствии насыщенных паров аммиака. На рис. 3, a приведены спектры пропускания, измеренные вне камеры на воздухе (кривая 1) и в камере до напуска газа (кривая 2). В окрестности длины волны $330 \mathrm{~nm}$ отмечена особенность - локальное уменьшение пропускания (прозрачности), связанное с проявлением поверхностного плазмонного резонанса (SPR) на тонкой плёнке серебра $(d \sim 3.6 \mathrm{~nm})$. Для снижения зашумленности спектров была проведена их обработка с помощью графического пакета Origin 8 (рис. 3,b). Уменьшение спектрального пропускания образца при его расположении в камере связано с дополнительным отражением света от входного окна камеры. Как видно, для всех спектральных линий в диапазоне длин волн от 550 до $900 \mathrm{~nm}$ отчетливо проявляется интерференция света.

При воздействии паров аммиака регистрация данных проводилась каждые две минуты. С увеличением времени экспозиции оптическая прозрачность мембраны ПАОА + Ag незначительно возрастала, особенно на длинных волнах. На рис. 4 приведены спектры оптического пропускания, измеренные через $2 \min ($ кривая 1 ) и $30 \mathrm{~min}$ (кривая 2) нахождения образца в потоке аммиака. Рост просветления образца на длинных волнах связан с увеличением оптического согласования по импедансу структуры с падающими электромагнитными волнами.

С помощью полученной интерференционной картины нетрудно определить показатель преломления мембраны для выбранной длины волны падающего света. Для двух соседних максимумов нормально падающего света соотношение (1) можно представить как

$$
2 n_{\mathrm{eff}} L=m \lambda_{1}, \quad 2 n_{\mathrm{eff}} L=(m+1) \lambda_{2} .
$$

Из соотношения (3) легко исключить порядок интерференционных полос $m$ и получить соотношение для эффективного показателя преломления $n_{\mathrm{eff}}$

$$
n_{\mathrm{eff}}=\frac{\lambda_{1} \lambda_{2}}{2 L\left(\lambda_{2}-\lambda_{1}\right)}
$$

С помощью соотношения (4) в узких спектральных частях интерференционного измеренного спектра для трёх выбранных длин волн $(650,750,850 \mathrm{~nm})$ определялись значения эффективного показателя преломления мембраны $n_{\mathrm{eff}}(\lambda)$. Полученные зависимости показателя преломления мембраны ПАОА $+\mathrm{Ag}$ от времени напуска газа в измерительную камеру приведены на рис. 5. Следует отметить тенденцию на рост показателя преломления для трёх длин волн - 650, 750, $850 \mathrm{~nm}$. Молекулярная пленка адсорбированного газа постепенно растёт со временем, что отражается в увеличении эффективного показателя преломления на длинах волн $650-850 \mathrm{~nm}$. 


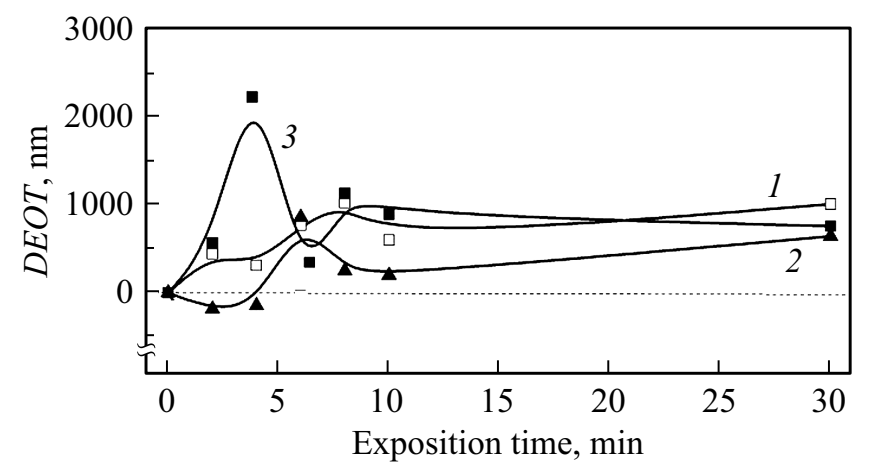

Рис. 6. Зависимости эффективной оптической толщины мембраны ПАОА $+\mathrm{Ag}$ от времени напуска газа в измерительную камеру на длинах волн 650 (1), 750 (2), $850 \mathrm{~nm}(3)$.

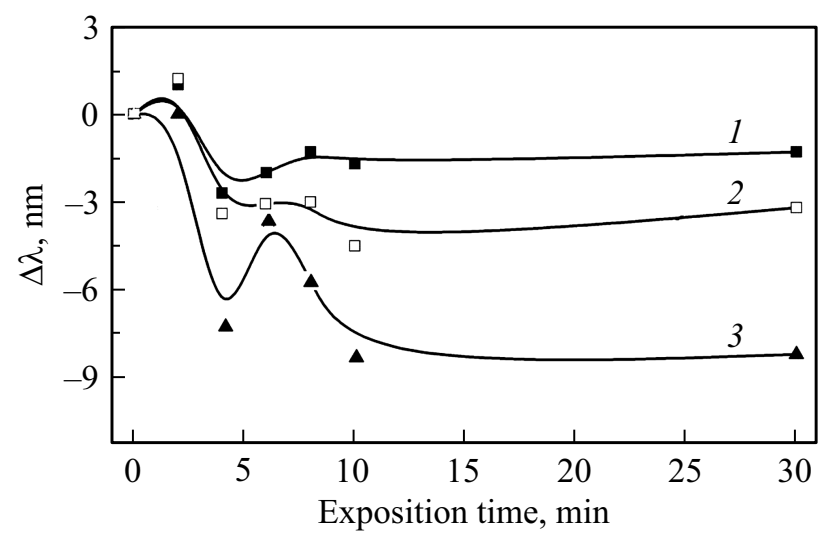

Рис. 7. Спектральный сдвиг положения максимума (минимума) в зависимости от времени напуска газа в измерительную камеру на длинах волн 650 (1), 750 (2), $850 \mathrm{~nm}(3)$.

Аналогичная тенденция проявляется в изменении эффективной толщины мембраны. На рис. 6 приведены зависимости DEOT мембраны ПАОА $+\mathrm{Ag}$ от времени напуска газа в измерительную камеру при различных длинах волн. Как видно из приведенных зависимостей, характер поведения DEOT подобен временным зависимостям эффективного показателя преломления для разных длин волн падающего света, что подтверждает правильность предположения для соотношения (2).

В подтверждение сказанному было проведено БФП интерференционных сигналов, измеренных в различные моменты времени на выбранных ранее длинах волн. Увеличение интенсивности фурье-спектра для волн $650-850 \mathrm{~nm}$ свидетельствует о росте толщины молекулярного адсорбированного слоя аммиака, в то время как снижение интенсивности спектра указывает на процессы десорбции газа на поверхности серебра. Следует отметить, что интенсивность неравновесных процессов адсорбции и десорбции максимальна в интервале времени от 4 до $10 \mathrm{~min}$.

$\mathrm{B}$ ходе воздействия газа на ПАОА $+\mathrm{Ag}$ наблюдается сдвиг интерференционных максимумов в коротковолновую область (синий сдвиг) на величину до $14 \mathrm{~nm}$ по сравнению с аналогичным значением при воздействии воздуха (рис. 7). Величина сдвига зависит от времени экспозиции и практически не меняется после $15 \mathrm{~min}$ выдержки рабочего образца в газовом потоке. Время в $15 \mathrm{~min}$, при котором наблюдается максимальный сдвиг интерференционных полос, можно отнести к времени установления равновесия или постоянной времени отклика оптического сенсора на основе использованного материала ПАОА $+\mathrm{Ag}$.

Газочувствительные свойства полученного $\mathrm{Ag} / \mathrm{Al}_{2} \mathrm{O}_{3}$ композита были протестированы по отношению к насыщенным парам летучих органических веществ (этанол, ацетон, изопропанол) в смеси с воздухом, однако существенного отклика получено не было. Значительный сенсорный отклик мембраны ПАОА $+\mathrm{Ag}$ был получен по отношению к насыщенным парам аммиака и объясняется высокой селективностью синтезированного материала к данному газу за счет комплексообразования [16] и подтверждается литературными сведениями $[17,18]$.

\section{Заключение}

Приведены результаты экспериментального исследования изменения интерференционных свойств оптически прозрачной мембраны ПАОА толщиной $4 \mathrm{mkm}$ со сквозными порами, покрытой тонкой $(3.6 \mathrm{~nm})$ туннельно прозрачной плёнкой серебра, в зависимости от времени нахождения в насыщенном газовом потоке аммиака с концентрацией $\sim 440 \mathrm{kppm}$ и скоростью $170 \mathrm{ml} / \mathrm{min}$. Изменения интерференционных свойств оптически прозрачной мембранной структуры ПАОА $+\mathrm{Ag}+$ молекулярная пленка исследовались в диапазоне длин волн от 550 до $900 \mathrm{~nm}$. При этом в качестве основной характеристики таких изменений была использована эффективная оптическая толщина мембраны, значения которой оценивались в течение $30 \mathrm{~min}$ с дискретной выборкой в $2 \mathrm{~min}$ на условно выбранных длинах волн 650,750 , $850 \mathrm{~nm}$. На основе измеренных спектров пропускания были получены временные и спектральные зависимости показателя преломления и изменения эффективной оптической толщины. Для полученных зависимостей показателя преломления мембраны ПАОА $+\mathrm{Ag}$ от времени напуска газа в измерительную камеру следует отметить тенденцию на рост показателя преломления для трёх длин волн $-650,750$ и $850 \mathrm{~nm}$. Методом БФП спектров пропускания показано, что интенсивность неравновесных процессов адсорбции максимальна в интервале времени от 4 до $10 \mathrm{~min}$.

$\mathrm{B}$ ходе воздействия аммиака на ПАОА $+\mathrm{Ag}$ наблюдался сдвиг интерференционных максимумов в коротковолновую область (синий сдвиг) на величину до $14 \mathrm{~nm}$ по сравнению с аналогичным значением при воздействии воздуха. Сдвиг практически не менялся после $10-15 \mathrm{~min}$ выдержки рабочего образца в атмосфере с газом. Поэтому время в $15 \mathrm{~min}$ можно оценивать как время установления равновесия или как постоянную времени 
отклика оптического сенсора на основе использованного материала ПАОА + Ag. Следует отметить, что при замене аммиака летучими органическими соединениями (этанол, ацетон, изопропанол) не выявлено изменений в интерференционной части спектра пропускания, что свидетельствует о селективности адсорбции аммиака на поверхности ПАОА + Ag.

\section{Финансирование работы}

Работа выполнена в рамках государственного задания „Сенсор“ и при финансовой поддержке грантов РФФИ № 19-32-90221 и № 20-07-00968.

\section{Конфликт интересов}

Авторы заявляют, что у них нет конфликта интересов.

\section{Список литературы}

[1] T. Kumeria, A. Santos, D. Losic. Sens., 14 (7), 11878 (2014). DOI: $10.3390 / \mathrm{s} 140711878$

[2] A. Yamaguchi, K. Hotta, N. Teramae. Anal. Chem., 81 (1), 105 (2009). DOI: $10.1021 /$ ac8015642

[3] A.G. Koutsioubas, N. Spiliopoulos, D. Anastassopoulos, A.A. Vradis, G.D. Priftis. J. Appl. Phys., 103, 094521 (2008). DOI: $10.1063 / 1.2924436$

[4] V.S.Y. Lin, K. Motesharei, K.P.S. Dancil, M.J. Sailor, M.R. Ghadiri. Science, 278 (5339), 840 (1997).

DOI: $10.1126 /$ science. 278.5339 .840

[5] C. Pacholski, L.A. Perelman, M.S. VanNieuwenhze, M.J. Sailor. Phys. Stat. Sol. A, 206 (6), 1318 (2009). DOI: $10.1002 /$ pssa.200881072

[6] F. Casanova, C.E. Chiang, A.M. Ruminski, M.J. Sailor, I.K. Schuller. Langmuir, 28 (17), 832 (2012). DOI: $10.1021 / 1 \mathrm{a} 204933 \mathrm{~m}$

[7] S. Pan, L.J. Rothberg. Nano Lett., 3 (6), 811 (2003). DOI: $10.1021 / \mathrm{n} 10340551$

[8] S.D. Alvarez, C.-P. Li, C.E. Chiang, I.K. Schuller, M.J. Sailor. ACS Nano, 3 (10), 3301 (2003). DOI: 10.1021/nn900825q

[9] T. Kumeria, D. Losic. Phys. Stat. Sol. Rapid Res. Lett., 5 (10-11), 406 (2011). DOI: 10.1002/pssr.201105425

[10] S. Kaur, C.S. Law, N.H. Williamson, I.M. Kempson, A. Popat, T. Kumeria, A. Santos. Anal. Chem., 91 (8), 5011 (2019). DOI: 10.1021 /acs.analchem.8b04963

[11] F. Casanova, C.E. Chiang, C.-P. Li, I.V. Roshchin, A.M. Ruminski, M.J. Sailor, I.K. Schuller. Nanotech., 19 (31), 315709 (2008). DOI: 10.1088/0957-4484/19/31/315709/

[12] A. Pistone, A. Piperno, D. Iannazzo. Sens. Actuators B, 186, 333 (2013). DOI: 10.1016/j.snb.2013.06.027

[13] H.O. Ali. Transact. IMF, 95 (6), 290 (2017). DOI: $10.1080 / 00202967.2017 .1358514$

[14] T. Kumeria, A. Santos. Electrochemically Engineered Nanoporous Materials (Springer, Cham, 2015). p. 187-218. DOI: 10.1007/978-3-319-20346-1_7

[15] M. Nemati, A. Santos, T. Kumeria, D. Losic. Anal. Chem., 87 (17), 9016 (2015). DOI: 10.1021/acs.analchem.5b02225

[16] А.Ю. Оленин. Журн. неорг. химии, 65 (4), 542 (2020). DOI: $10.31857 / \mathrm{S} 0044457 \mathrm{X} 20040157$
[17] B. Wu, X. Zhang, B. Huang, Y. Zhao, C. Cheng, H. Chen. Sens., 17 (9), 2070 (2017). DOI: 10.3390/s17092070

[18] D. Kwak, Y. Lei, R. Maric. Talanta, 204, 713 (2019). DOI: $10.1016 /$ j.talanta.2019.06.034 